\title{
Izobraževanje o načrtovanju zdravstvenih pregledov rastlin in ukre- panju ob izbruhih škodljivih organizmov v gozdarstvu, Benetke april 2018
}

\section{Nikica OGRIS*}

Udeležili smo se petdnevnega izobraževanja o zdravstvenem varstvu rastlin na temo ukrepanja ob izbruhih škodljivih organizmov rastlin in načrtovanja zdravstvenih pregledov rastlin $\mathrm{v}$ gozdarstvu, vključno $\mathrm{z}$ urbanim okoljem. Izobraževanje je potekalo v Benetkah od 23. do 27. aprila $2018 \mathrm{v}$ organizaciji iniciative BTSF (angl. Better Training for Safer Food), ki jo financira
Evropska komisija. Na izobraževanju je bilo 30 udeležencev iz štirinajstih držav članic ES (slika 1). Iz Slovenije sva se izobraževanja udeležila Andrej Držaj, vodja odseka za gojenje in varstvo gozdov na območni enoti Novo mesto Zavoda za gozdove Slovenije, in dr. Nikica Ogris, vodja Poročevalske, Prognostično-diagnostične službe za gozdove na Gozdarskem inštitutu Slovenije.

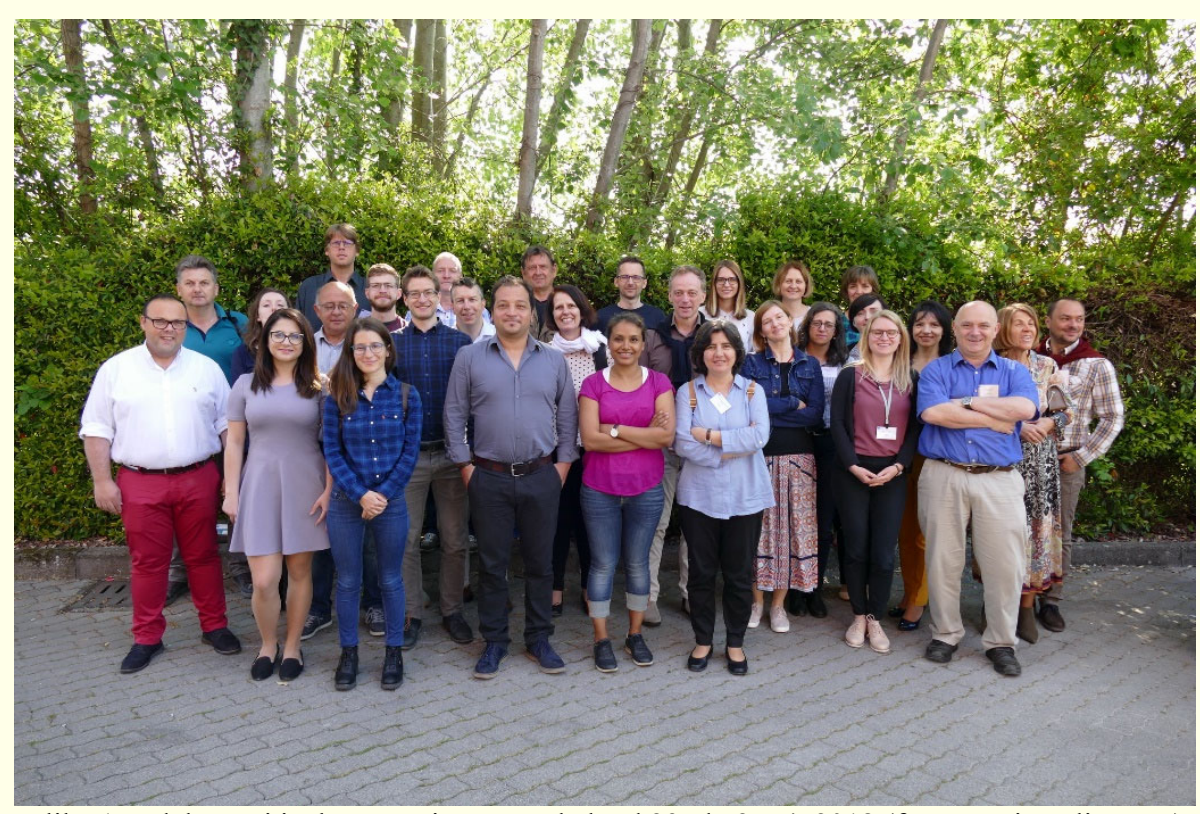

Slika 1: Udeleženci izobraževanja v Benetkah od 23. do 27. 4. 2018 (foto: Marius Flintoaca)

Izobraževanje je bilo sestavljeno iz predavanj in praktičnih vaj v skupinah, skupaj je bilo 17 sej. V uvodu smo obnovili osnove zakonodaje s področja zdravstvenega varstva rastlin s poudarkom na zdravstvenih pregledih in ukrepanju v primeru izbruhov škodljivih organizmov. Nadaljevali smo s spoznavanjem sprememb, ki jih uvaja nova Uredba 2016/2031 Evropskega parlamenta in Sveta $\mathrm{z}$ dne 26. oktobra 2016 o ukrepih varstva pred škodljivimi organizmi rastlin, ki bo zamenjala trenutno veljavno direktivo 2000/29/ES in še nekatere druge s področja zdravstvenega varstva rastlin. Nova uredba bo začela veljati 14. decembra 2019. Nato sta sledila predavanje in vaja o načrtovanju izvedbe programov preiskav škodljivih organizmov s poudarkom na zdravstvenih pregledih in vzorčenju. Spoznali smo, kako pravilno izbrati mesta pregledov glede na tveganje: prednost damo mestu, kjer je večja verjetnost, da bomo našli škodljiv organizem. Pomembno je pravilno izbrati velikost vzorca. Navodilo za to daje mednarodni standard ISPM, št. 31, ki ga je sprejel IPPC (International
Plant Protection Convention). Velikost vzorca je odvisna od predvidene ravni okužbe/napada, verjetnosti zaznave škodljivega organizma in velikosti populacije.

$\mathrm{V}$ drugem dnevu izobraževanja smo obiskali mesto Cornuda, kjer so ugotovili izbruh azijskega kozlička (Anoplophora glabripennis, slika 2). Prvo najdbo omenjenega škodljivca na tamkajšnjem območju so zabeležili v letu 2009. Izbruh je trajal vse do leta 2015 . V zadnjih dveh letih, od 2016 do 2018, niso več našli novih napadenih dreves, zato so izkoreninjanje razglasili za uspešno in končali redno spremljanje. V obdobju od 2009 do 2015 so našli 1157 napadenih dreves. Najpogosteje je škodljivec napadel javor, brest, brezo in vrbo, redkeje pa divji kostanj, češnjo in topol. Posekali so dvakrat več dreves (2428), kot jih je bilo napadenih, saj so posekali vsa gostiteljska drevesa $\mathrm{v}$ polmeru $100 \mathrm{~m}$, spremljali pa so kar 36.361 dreves. Vsako napadeno drevo je obkrožal varovalni pas v polmeru $2 \mathrm{~km}$. Načrt izkoreninjanja je vključeval: inventuro vseh potencialnih gostiteljskih dreves, zdravstveni pregled vseh dreves $\mathrm{v}$ polmeru $2 \mathrm{~km}$ od vsakega napadenega drevesa, posek 
napadenih dreves in izdelavo $\mathrm{v}$ sekance, sajenje nadomestnih dreves (drevesna vrsta, ki ni gostiteljica azijskega kozlička), kampanjo javnega obveščanja. Prepovedano je bilo: (1) kakršenkoli premik ali prodaja dovzetnih vrst dreves zunaj varovalnega pasu; (2) premik odpadnega lesa, ki ni bil prej predelan v sekance, zunaj varovalnega pasu; (3) sajenje občutljivih drevesnih vrst. Uspešno izkoreninjanje azijskega kozlička v mestu Corduna je primer dobre prakse, dobrega načrtovanja in upravljanja žarišča karantenskega škodljivega organizma. Azijski kozliček naseljuje debelejše veje in zgornji del debla. Zato je za učinkovit zdravstveni pregled potreben izurjen tim plezalcev (slika 3). Obvezna oprema vsakega preglednika vključuje daljnogled, fotoaparat, GPS, nož, lupo, pršilo in trak za označevanje (slika 4).

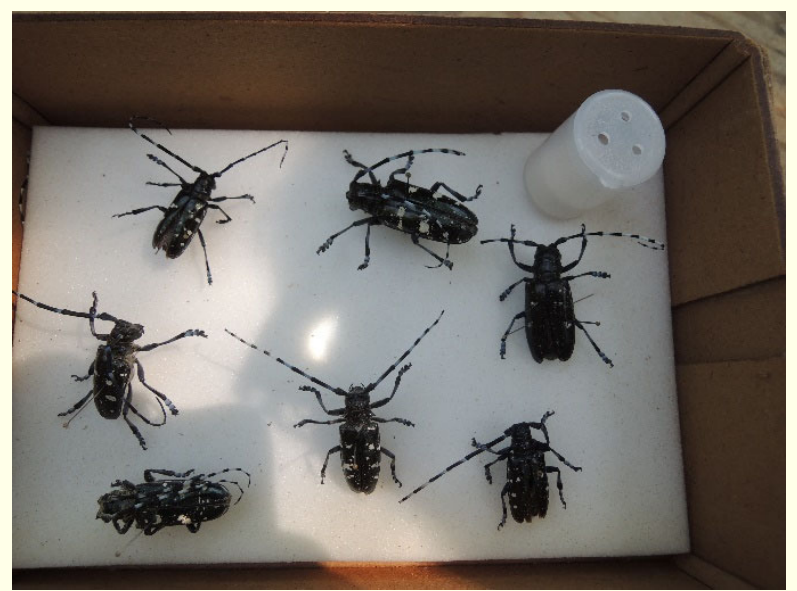

Slika 2: Azijski kozlički (Anoplophora glabripennis), ki so jih ujeli v mestu Cornuda v Italiji (foto: N. Ogris)

Tretji dan izobraževanja smo obravnavali metode ocenjevanja zdravja gozdov, vključno z vizualnimi pregledi, uporabo pasti, posekom dreves in metodami daljinskega zaznavanja. Spoznali smo, kako v danem primeru izbrati pravilno metodo. Potem smo obravnavali primere pomembnih karantenskih škodljivih organizmov, kot so: borova ogorčica (Bursaphelenchus xylophilus), kitajski kozliček (Anoplophora chinensis) in azijski kozliček (A. glabripennis). Seznanili smo se z njihovim trenutnim stanjem v svetu in Evropi, znaki napada, načinom širjenja, poškodbami, ki jih povzročajo, katere rastline in njihovi proizvodi predstavljajo največje tveganje za vnos, kateri ukrepi so potrebni v primeru najdbe, usmeritve za izvedbo zdravstvenih pregledov in vzorčenja. Posebno predavanje je bilo namenjeno sofinanciranju zdravstvenih pregledov, kar določa Uredba (EU), št. 652/2014, Evropskega parlamenta in Sveta z dne 15. maja 2014. Ob tem smo pozornost namenili škodljivim organizmom, ki so na prioritetnem seznamu; to so npr. azijski ambrozijski podlubnik (Xylosandrus crassiusculus), sahalinski jelov ličar (Polygraphus proximus), borov smolasti rak (Fusarium circinatum), bolezen tisočerih rakov (Geosmithia morbida in njen vektor Pityophthorus juglandis). Sledilo je predavanje o obveznostih poročanja v IPPC, EPPO, ES, v katerem smo izvedeli, da mora država članica ES sporočiti najdbo karantenskega organizma $\mathrm{v}$ osmih dneh po njegovi potrditvi. Najdbo je treba sporočiti tudi preko elektronskega informacijskega sistema EUROPHYT, ki vse članice takoj obvesti o novi najdbi.
Iz Moskve se proti zahodni Evropi širi jesenov krasnik (Agrilus planipennis). Hrošča so našli že tik ob meji z Belorusijo in Ukrajino. Širi se hitro, tj. ok. 20 km/leto. Poleg jesena napada tudi breste, orehe in krilatega oreškarja. Poleg jesenovega krasnika je veliko tveganje za vnos brezovega krasnika (A. anxius), ki napada samo breze in je trenutno razširjen samo v Severni Ameriki. Najbolj priporočljiv način vzorčenja je odstranjevanje posušenih in sušečih se vej v krošnji, za kar lahko uporabimo teleskopsko žago, če so drevesa nižja. Za višja drevesa pa je za vzorčenje nujno potreben izurjen plezalec.

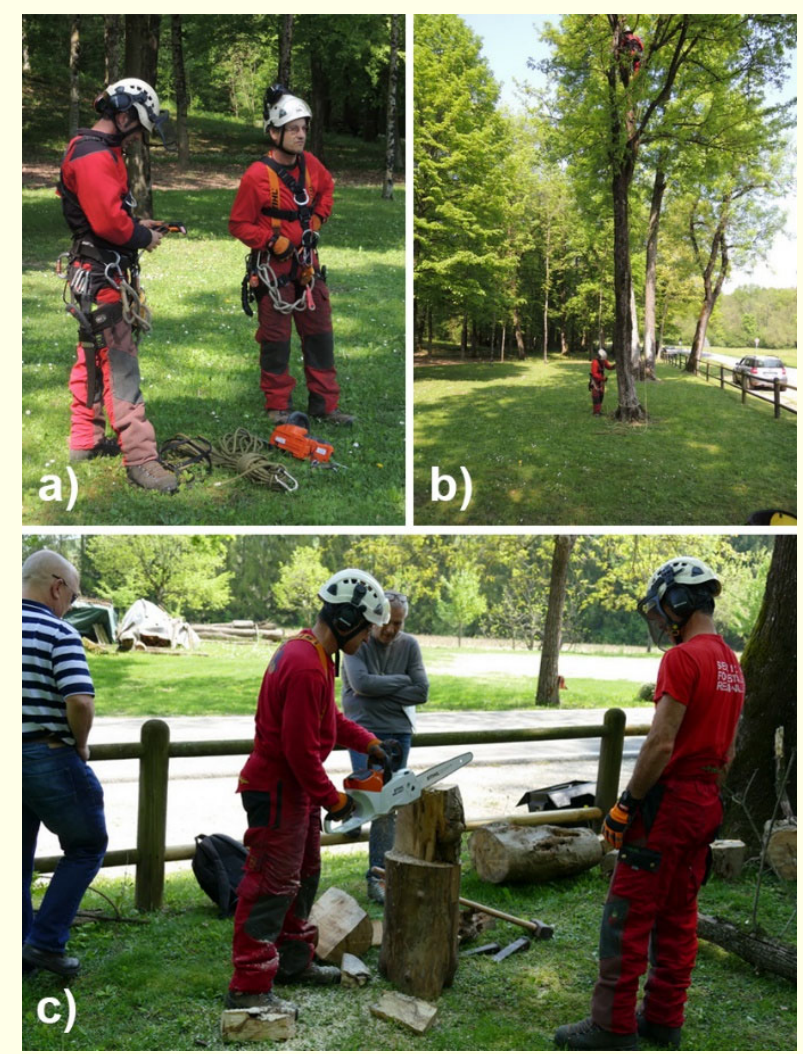

Slika 3: (a) Izurjeni tim plezalcev je nujen pri izvajanju zdravstvenih pregledov za ugotavljanje napada azijskega kozlička (foto: N. Ogris); (b) Plezalec v krošnji išče simptome napada azijskega kozlička, drugi plezalec na tleh mu pomaga: po vrvi mu pošlje električno motorno žago (foto: N. Ogris); (c) Plezalec je odžagal sumljivo vejo in na tleh išče simptome (rove, ličinke, odrasle žuželke) v veji, tako da vejo žaga na manjše kose (foto: Marius Flintoaca).

Pri učinkovitem boju proti vneseni invazivni tujerodni vrsti je pomembna tudi izmenjava informacij. Uspešna komunikacija vključuje več komunikacijskih kanalov: mediji (televizija, radio), spletne strani, tiskane publikacije (letaki, brošure), srečanja in delavnice, družbena omrežja. Pri informiranju javnosti moramo vedeti, katere so ciljne skupine, da zanje ustrezno pripravimo gradivo in pravilno izberemo komunikacijski kanal. Ker je možnost izkoreninjanja škodljivega organizma večja, če ga zaznamo zgodaj, je pomembno ozaveščanje javnosti o nevarnosti ITV še pred njegovim prihodom in širjenjem. Komunikacijske kampanje so navadno drage; v Italiji so npr. za komunikacijsko kampanjo o kitajskem kozličku v Milanu v letu 2018 porabili ok. $150.000 €$, največji strošek je bil video, ki so ga predvajali na televiziji (ok. $40.000 €$ ). 
$\mathrm{V}$ novi uredbi ES o zdravstvenem varstvu rastlin 2016/2031 posebej obravnavajo nekarantenske regulirane škodljive organizme. Če najdemo škodljiv organizem, ki ni na seznamu karantenskih škodljivih organizmov, država članica pa ugotovi, da izpolnjuje vse pogoje, da bi bil lahko uvrščen v prilogo 1 ali 2 Uredbe, mora o najdbi takoj obvestiti druge države članice in Evropsko komisijo. Poleg tega mora takoj začeti izvajati ukrepe za izkoreninjanje. Ob prvi najdbi neznanega škodljivega organizma je priporočeno, da v prvih 24-tih urah naredimo hitro oceno tveganja glede na poti morebitnih prenosov, glede na ogrožene gostitelje, ustreznost podnebja in potencialni vpliv škodljivega organizma.

Če karantenskega škodljivega organizma nismo uspeli izkoreniniti v treh letih od vnosa, v večini primerov velja, da je na nekem območju ustaljen. Zato spremenimo strategijo iz izkoreninjenja $v$ zadrževanje, kar pomeni, da izvajamo fitosanitarne ukrepe na napadenem območju in okoli njega, da bi preprečili nadaljnje širjenje škodljivega organizma. Za strategijo zadrževanja se lahko odločimo tudi takrat, ko ni na voljo učinkovitih ukrepov za izkoreninjanje ali nimamo na voljo dovolj sredstev (ljudi in denarja).

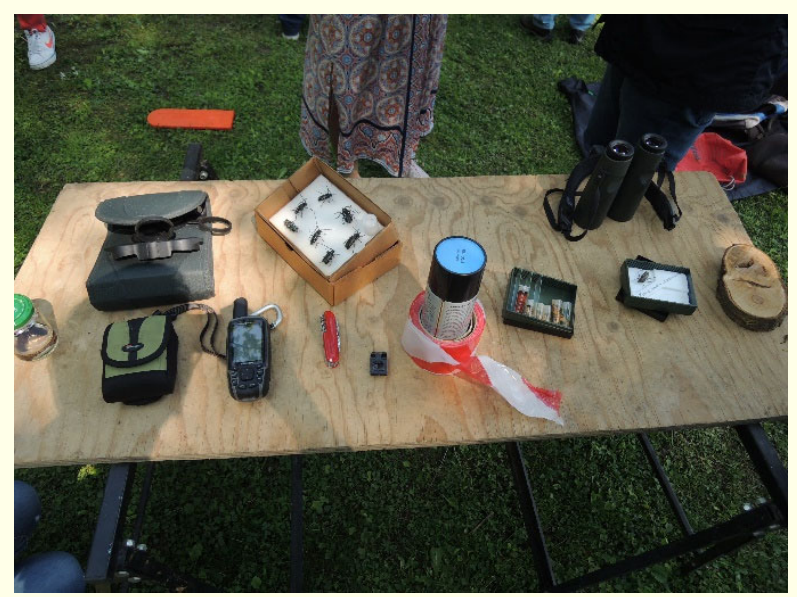

Slika 4: Obvezna oprema vsakega preglednika vključuje daljnogled, fotoaparat, GPS, nož, lupo, sprej in trak za označevanje (foto: N. Ogris).

Na izobraževanju v Benetkah smo se seznanili tudi s temo o načrtovanju ukrepov (angl. Contingency planning). Navadno se načrt ukrepov pripravi vnaprej, še preden najdemo škodljiv organizem. Pripravljen načrt ukrepov ima mnogo prednosti: omogoča hiter odziv in predhodni poglobljen razmislek o različnih možnostih, deležniki imajo možnost vplivati na izbiro ukrepov, lahko odkrije pomanjkljivosti $v$ trenutni organizaciji fitosanitarne službe. Poznamo več vrst načrtov ukrepov: splošen, specifičen in izvedbeni načrt. Splošen načrtov ukrepov opisuje generalno organizacijo v primeru pojava pomembnega škodljivega organizma. Specifičen načrt ukrepov se pripravi za določen škodljiv organizem, izvedbeni pa za določen izbruh in opisuje, katere naloge bo kdo opravil in kdaj. Vsebina načrta ukrepov je definirana v Uredbi EU 2016/2031. Uredba določa tudi, da je treba za uresničitev načrta ukrepov v rednih intervalih izvajati simulacijske vaje skupaj z vsemi pomembnimi deležniki. Načrti ukrepov za škodljive organizme s prioritetnega seznama morajo biti pripravljeni do leta 2023.

$\mathrm{V}$ eni izmed vaj (delo v skupinah) smo obravnavali primer, da pooblaščeni laboratorij obvestijo o potencialni najdbi jesenovega krasnika $\mathrm{v}$ petek popoldan ob 16.30 , ko navadno vsi končujejo z delom in pričakujemo vikend. Naloga je bila: katere ukrepe bi izvedli takoj v petek ob 16.30 in kasneje, ko bi določitev potrdil entomolog. Tak hudomušen primer ima tudi kanček resnice, saj se pogosto zgodi, da laboratorij sprejme vzorce tudi $\mathrm{v}$ petek pozno popoldan, ko je večina zaposlenih v laboratoriju že končala z delom. Prvi korak je pridobiti vzorec, na podlagi katerega bo pooblaščeni laboratorij (entomolog) potrdil, ali res gre za jesenovega krasnika. Poleg omenjenega specifičnega primera za vajo smo obravnavali tudi splošne ukrepe za izkoreninjenje jesenovega krasnika: posek vseh napadenih dreves, posek vseh jesenov (gostiteljskih dreves) v polmeru vsaj 100 $\mathrm{m}$, zdravstveni pregled vseh gostiteljev v polmeru vsaj 1 $\mathrm{km}$, varovalni pas polmera vsaj $20 \mathrm{~km}$, kjer je prepovedan premik napadenega materiala zunaj varovalnega pasu. Izkušnje iz ZDA in Kanade, kjer se borijo proti jesenovemu krasniku že dalj časa, kažejo, da so ukrepi za izkoreninjanje in zadrževanje jesenovega krasnika izjemno zahtevni. Zato je bistveno preprečiti vnos.

O uspešnosti izobraževanja pričajo tudi rezultati preskusa znanja, ki smo ga opravili vsi udeleženci dvakrat: prvič čisto na začetku tečaja in ponovno na koncu. Preskus znanja je obsegal 31 vprašanj. Pred začetkom izobraževanja je skupina udeležencev imela povprečno oceno 48,8 \% pravilnih odgovorov. Po koncu izobraževanja se je ocena bistveno dvignila, tj. povprečen delež pravilnih odgovorov je bil 78,3\%. Rezultati preskusa dokazujejo, da smo na izobraževanju bistveno zvišali nivo znanja. Slednje lahko potrdim tudi sam. Udeleženci smo dobili teoretične in praktične izkušnje $z$ načrtovanjem zdravstvenih pregledov in upravljanjem izbruhov škodljivih organizmov. Poleg tega smo izmenjali dobre prakse in izkušnje na tem področju. S pridobljenim znanjem smo bolje pripravljeni na hitro ukrepanje v primeru vnosa karantenskega organizma v Slovenijo.

\section{Zahvala}

Zahvaljujemo se Upravi za varno hrano, veterinarstvo in varstvo rastlin, ki je je predlagalo in rezerviralo izobraževanje BTSF v Benetkah v letu 2018. Stroške, povezane z izobraževanjem, je poravnala Javna gozdarska služba na Gozdarskem inštitutu Slovenije, naloga 2B, ki jo financira Ministrstvo za kmetijstvo, gozdarstvo in prehrano.

\author{
Gozdarski inštitut Slovenije, Večna pot 2, 1000 Ljubljana, Slovenija \\ *nikica.ogris@gozdis.si
}

